Como citar: Santos, S. S., Feijo, L. P., Farias, T. M., \& Poletto, M. (2020). Parecer Branco para não Ser Discriminado? Revisão Sistemática sobre Estratégias de Embranquecimento. PSI UNISC, 4(2), 114-130. doi: $10.17058 /$ psiunisc.v4i2.14829

\title{
Parecer Branco para não Ser Discriminado? Revisão Sistemática sobre Estratégias de Embranquecimento
}

\author{
Para Parecer Blanco y no Ser Discriminado? Revisión Sistemática de las Estrategias \\ de Blanqueamiento
}

\author{
Look White so as not Being Discriminated Against? Systematic Review about \\ Whitening Strategies
}

\author{
Sabrina Silva Santos \\ Instituto Brasileiro de Gestão de Negócios (IBGEN), Porto Alegre - RS/Brasil \\ ORCID: 0000-0001-5750-5534 \\ E-mail: sabrina.silsan@gmail.com
}

Luan Paris Feijo

Universidade do Vale do Rio dos Sinos (Unisinos), Porto Alegre - RS/Brasil ORCID: 0000-0002-7587-3987

E-mail: lparisf@gmail.com

Thaise Mendes Farias

Universidade do Vale do Rio dos Sinos (Unisinos), Porto Alegre - RS/Brasil ORCID: 0000-0001-9821-3247

E-mail: psicologa.thaisefarias@gmail.com

Michele Poletto

Universidade Federal do Rio Grande do Sul (UFRGS), Porto Alegre - RS/Brasil ORCID: 0000-0002-5915-8406

E-mail: michelepolettopsi@gmail.com

\begin{abstract}
Resumo
O estudo objetivou compreender como o individuo negro vivencia o processo de "branqueamento". Foram revisadas sistematicamente as publicações na literatura nacional indexada nas bases de dados SCIELO, PePSIC e LILACS. Através dos descritores "padrão estético", "estética racial", "branqueamento racial" e "identidade racial", foram selecionados 20 artigos. Observou-se que a discriminação racial, sofrida pelos indivíduos negros, pode causar uma tendência ao autobranqueamento, como forma de proteção em relação à discriminação e enquadramento no padrão hegemônico. Constatou-se, também, que estes indivíduos usam estratégias de resistência frente ao processo de branqueamento, de forma a ressignificar sua identidade negra.
\end{abstract}

Palavras-chaves: Estética racial; Branqueamento racial; Identidade racial.

\section{Resumen}

El estudio tenía como objetivo entender los efectos de la discriminación en la identidad de los individuos negros brasileños. Se examinaron sistemáticamente las publicaciones de la literatura nacional indizada en las bases de datos SCIELO, PePSIC y LILACS. A través de los descriptores "patrón estético", "estética racial", "blanqueamiento racial" e "identidad racial", se seleccionaron 20 artículos. Se observó que la discriminación racial, sufrida por los individuos negros, puede causar una tendencia a la autodeclaración, como una forma de protección contra la discriminación y enmarcada en el patrón hegemónico. También se encontró que estos individuos utilizan estrategias de resistencia al proceso de blanqueamiento, para resignificar su identidad negra.

Palabras clave: Estética racial; Blanqueamiento racial; Identidad racial. 


\begin{abstract}
This research aimed to understand the effects of racial discrimination in identity formation of black brazilian individuals. Publications in the national literature indexed in the databases SCIELO, PePSIC and LILACS were systematically reviewed. 20 articles were selected through the descriptors "aesthetic standard", "racial aesthetics", "racial whitening" and "racial identity". It was observed that the racial discrimination suffered by
\end{abstract}

black individuals can induce a tendency to "self whitening" as a form of protection from discrimination and from the position of the hegemonic standard. However, we found out that these individuals take strategies of resistance against the whitening process, in a way to resignify their black identity.

Keywords: Racial aesthetics; Racial whitening; Racial identity

\section{Introdução}

O processo de "branqueamento", em um primeiro momento, possuiu como característica a forte miscigenação ocorrida entre indivíduos brancos e pretos no período de colonização (Lacerda, 1911). Em consequência, houve um crescente número populacional de indivíduos mestiços brasileiros, superior ao número de pretos e brancos (Instituto Brasileiro de Geografia e Estatistica [IBGE], 2013). Contudo, o branqueamento também é definido como a pressão cultural que exerce a hegemonia branca para minimizar as características afrodescendentes e assemelhar-se aos brancos, principalmente após a abolição da escravatura. Já naquela época este processo oprimia o descendente de africanos escravizados de forma que esse "negasse a si mesmo, no seu corpo e na sua mente, como uma espécie de condição para se integrar, ser aceito e ter mobilidade social, na nova ordem mundial" (Carone, 2012, p.14).

A história do indivíduo negro brasileiro que é o sujeito preto ou o miscigenado com acentuadas características fenotípicas negroides, conforme explica Munanga (2004b) é marcada por adversidades desde à época da escravidão, sobretudo, em virtude do racismo, o qual se define por uma sistemática discriminação fundamentada na raça e que é manifestada por práticas intencionais ou não que originam desvantagens ou privilégios dependendo do grupo racial pertencente (Almeida, 2018). O racismo se estabeleceu em um contexto histórico e social que se caracterizou pelo surgimento do conceito de raça na contemporaneidade.
O termo surgiu a partir do século XVI, baseado em ideias e valores da civilização europeia quando esta passou a ter contato com outros grupos étnicos, sendo então consolidado pelos construtos científicos acerca de raça no século XIX. Contudo, avanços conquistados nas ciências biológicas e genéticas, concluíram que biologicamente não existiria o conceito de raça, pois os mesmos marcadores genéticos poderiam ser encontrados em indivíduos pretos, brancos ou amarelos. Portanto, as heranças genéticas existentes entre os seres humanos não seriam suficientes para classificação em raças (Schucman, 2010).

Mesmo superada a ideia de raça pelas ciências biológicas, ainda hoje, o racismo produz efeitos e um deles é o preconceito racial, o qual é caracterizado pela concepção antecipada e negativa a respeito de indivíduos de outras raças, sem que haja motivo ou razão (Lima, \& Vala, 2004). A ação ou atitude de discriminar estes indivíduos, com base nestas construções preconceituosas, é definida como discriminação racial (Valente, 1998). A discriminação promove a supervalorização de uma cultura em prol de outra e acarreta ao dominador o sentimento de superioridade e, ao dominado, inferioridade (Lopes, 2005).

Além disto, Gomes (2004) aborda que a cor da pele e o tipo de cabelo são as características mais discriminadas e objeto de racismo contra o indivíduo negro. No entanto, elas são os referenciais de identificação e pertença da ancestralidade africana. $\mathrm{O}$ afrodescendente é submetido a um sistema que define como inferior seus valores e atributos e, ao introjetar tais constructos, nega a si mesmo enquanto indivíduo negro (Munanga, 2004a). Assim, afirmar positivamente a identidade 
negra, em uma sociedade que a estigmatiza, pode ser um processo complexo para o indivíduo negro (Gomes, 2004; Munanga, 2004a).

A identidade é construída na coletividade, onde o indivíduo percebe a si mesmo tendo o outro como referência. Esta construção contínua, que pode ocorrer de maneira consciente e inconsciente, se processa no contexto privado, através das relações familiares, e no contexto público, através das relações sociais mais amplas (Costa, 1983; Gomes, 2004). Contudo, considerando que o indivíduo negro se destoa do padrão branco hegemônico, esse sofreria com a depreciação de suas características fenotípicas percebidas como negativas por si próprio e pelos demais. Desta forma, tenderia a adotar procedimentos para alterar sua realidade corporal e social a fim de se aproximar do padrão ideal e, para isso, assumindo um estereótipo de comportamento que julga ser do indivíduo branco e o qual acredita ser superior - e ao mesmo tempo, também estaria protegendo-se de ser alvo de discriminação racial (Costa, 1983).

Diante desse exposto, o presente estudo possui como objetivo compreender como o individuo negro vivencia o processo de "branqueamento". Para tal propósito, realizouse uma revisão sistemática da literatura brasileira para identificar e discutir as vivências deste processo em participantes negros.

\section{Método}

As etapas para construção desta revisão sistemática incluíram: (1) formulação e delimitação da questão de pesquisa; (2) escolha das fontes de dados; (3) eleição das palavraschave; (4) busca e organização dos resultados; (5) seleção dos artigos pelo resumo; (6) extração dos dados nos artigos selecionados; (7) avaliação dos artigos e (8) síntese e interpretação dos dados (Costa \& Zoltowski, 2014). Essa revisão sistemática seguiu as recomendações do Preferred Reporting Items for Systematic Reviews and Meta-Analyses PRISMA (Moher, Liberati, Tetzlaff, \& Altman, 2009).
Os descritores utilizados para a busca foram: "padrão estético", "estética racial", "branqueamento racial" e "identidade racial". Estes foram inseridos, separadamente, nas bases de dados consultadas, a saber: Periódicos Eletrônicos de Psicologia (PePSIC), Scientific Electronic Library Online (SciELO) e Literatura Latino-americana e do Caribe em Ciências da Saúde (LILACS), sendo a busca foi realizada por dois juízes independentes.

Os critérios de inclusão foram: artigos em idioma português (Brasil), com os textos na íntegra disponibilizados nas bases de dados selecionadas; artigos que apresentassem resultados com base em entrevistas com indivíduos negros, independente da faixa etária, gênero ou condição socioeconômica e artigos publicados entre os anos de 2000 a 2018. Os critérios de exclusão utilizados foram: teses, dissertações, trabalhos de conclusão, livros, resenhas, editoriais e relatórios científicos; artigos repetidos em mais de uma base de dados; artigos em idioma estrangeiro e estudos que não respondessem ao problema de pesquisa.

Realizada a leitura e análise dos títulos e seus respectivos resumos, aqueles que não responderam ao problema de pesquisa foram excluídos, bem como, os artigos repetidos. Assim, os artigos selecionados foram lidos na íntegra por dois juízes independentes que também tabularam individualmente estes estudos. Os casos divergentes foram resolvidos por consenso. Os artigos foram agrupados em unidades de significado (categorias) que emergiram da sua própria leitura.

\section{Resultados e discussão}

$\mathrm{Na}$ base de dados PePSIC foram encontrados 23 artigos, sendo 3 a partir do descritor "padrão estético", nenhum resultado para o descritor "estética racial", 5 pelo uso do descritor "branqueamento racial" e 15 com o uso do descritor "identidade racial". Nesta base foi selecionada 1 publicação. O SciELO apresentou um total de 158 artigos, sendo 28 com o uso do descritor "padrão estético", 10 pelo uso do descritor "estética racial", 10 com 
o uso do descritor "branqueamento racial" e 110 com o uso do descritor "identidade racial", foram selecionados 13 estudos. Por fim, a base de dados LILACS resultou em um total de 215 artigos, sendo 121 pelo uso do descritor "padrão estético", 19 a partir do descritor "estética racial", 11 com o uso do descritor "branqueamento racial" e 64 com o uso do descritor "identidade racial" e foram selecionados 6 artigos.
Foram excluídos 376 artigos com as seguintes características: 7 repetidos; 8 não indexados nas bases consultadas; 51 em idioma estrangeiro; 126 relacionados à área médica e/ou às questões envolvendo saúde pública; 184 envolvendo estudos sociológicos sobre relações e/ou comportamentos sociais, mas que não respondiam ao problema de pesquisa. A Tabela 1 exemplifica os motivos para exclusão dos artigos.

Tabela 1

Artigos excluídos

\begin{tabular}{cc}
\hline Categoria & Número de artigos \\
\hline Sociologia & 184 \\
Área médica/saúde pública & 126 \\
Idioma estrangeiro & 51 \\
Não indexado & 8 \\
Repetidos & 7 \\
\hline Resultado Total & $\mathbf{3 7 6}$ \\
\hline
\end{tabular}

Nota: Tabela elaborada pelos autores.

Na Tabela 2 apresentam-se os dados referentes aos 20 estudos incluídos na pesquisa. As informações contemplam: título, autores, ano de publicação, periódico e cidade onde foi realizado $o$ estudo. Os artigos foram relacionados em ordem crescente do ano de publicação. Para análise final foram constituídas categorias que descrevem (1) informações sociodemográficas dos participantes nestes estudos e (2) os contornos do processo de "embranquecimento". Tal processo, de acordo com o material elegido, é composto pelas categorias (a) tornar-se branco para ser aceito; (b) estratégias de resistência frente ao processo de branqueamento; (c) ressignificação da identidade negra e (d) mito da democracia racial.

Tabela 2

Artigos incluídos

\begin{tabular}{|c|c|c|c|c|c|}
\hline Título & Autores & Ano & Periódico & Objetivo do estudo & $\begin{array}{c}\text { Tipo de } \\
\text { pesquisa }\end{array}$ \\
\hline $\begin{array}{l}\text { 1. Trajetórias escolares, } \\
\text { corpo negro e cabelo } \\
\text { crespo: reprodução de } \\
\text { estereótipos ou } \\
\text { ressignificação cultural? }\end{array}$ & Gomes & 2002 & $\begin{array}{l}\text { Revista } \\
\text { Brasileira de } \\
\text { Educação }\end{array}$ & $\begin{array}{l}\text { Compreender o significado social do } \\
\text { cabelo e do corpo e os sentidos a eles } \\
\text { atribuídos pela escola e pelos sujeitos } \\
\text { negros entrevistados }\end{array}$ & $\begin{array}{c}\text { Pesquisa } \\
\text { etnográfica }\end{array}$ \\
\hline $\begin{array}{l}\text { 2. Educação, identidade } \\
\text { negra e formação de } \\
\text { professores/as: um olhar } \\
\text { sobre o corpo negro e o } \\
\text { cabelo crespo }\end{array}$ & Gomes & 2003 & $\begin{array}{l}\text { Revista } \\
\text { Brasileira de } \\
\text { Educação }\end{array}$ & $\begin{array}{l}\text { Representações e as concepções sobre o } \\
\text { corpo negro e o cabelo crespo, construídas } \\
\text { dentro e fora do ambiente escolar }\end{array}$ & $\begin{array}{l}\text { Pesquisa } \\
\text { qualitativa }\end{array}$ \\
\hline $\begin{array}{c}\text { 3. Percepção do racismo } \\
\text { no Rio de Janeiro }\end{array}$ & $\begin{array}{l}\text { Oliveira } \\
\text { \& Barreto }\end{array}$ & 2003 & $\begin{array}{l}\text { Estudos Afro- } \\
\text { Asiáticos }\end{array}$ & $\begin{array}{c}\text { Investigar a política de identidade racial } \\
\text { entre a população do Estado do Rio de } \\
\text { Janeiro e, de outro lado, testar a acuidade } \\
\text { da metodologia de classificação segundo } \\
\text { cor e raça utilizada pelo Instituto } \\
\text { Brasileiro de Geografia e Estatística - } \\
\text { IBGE }\end{array}$ & $\begin{array}{c}\text { Pesquisa } \\
\text { quantitativa }\end{array}$ \\
\hline
\end{tabular}


4. O fracasso escolar de meninos e meninas: articulações entre gênero e cor/raça

5. Política racial afirmativa e afetiva na interação intergrupal

6. Diferenças socioeconômicas entre autoclassificação e heteroclassificação de cor/raça

7. Modos de subjetivação de mulheres negras: efeitos da discriminação racial

8. Negritude e infância: relações étnico-raciais em situação lúdica estruturada

9. Pobreza, relações étnico-raciais e cotidiano escolar: narrativas do viver

\footnotetext{
10. As Relações cotidianas e a construção da identidade negra
}

\section{Sociabilidade} juvenil, cor, gênero e sexualidade no baile charme carioca

12. Das batalhas identitárias às práticas de liberdade: histórias de vida de uma professora negra

\section{Processos de identidade social e exclusão racial na infância da solidão \\ Máximo, \\ Larrain, \\ Nunes \& \\ Lins}

14. O paradoxo da mistura identidades, desigualdades e percepção de discriminação entre brasileiros pardos* \& Vargas

Carvalho $2004 \quad \begin{gathered}\text { Cadernos } \\ \text { Pagu }\end{gathered}$

Nery \&

Conceição

2006

Interação em

Psicologia

Bastos,

Peres,

Dumith \&

Gigante

2008

Revista Saúde Pública

Oliveira,

Meneghel \&

2009

Psicologia e Sociedade

Bernardes

Silva \&

Branco

Medeiros

2011

Psico

Revista

2011 Brasileira de

Educação

Ferreira \& Camargo

Cecchetto, Monteiro

Silva,

Moura \&

Lopes

2012

Psicologia

Política

Psicologia:

Ciência e

Profissão

Cadernos de Pesquisa

Linguagem em (Dis)curso

Silva \& Leão

Revista

Brasileira de

Ciências

Sociais
Conhecer os processos através dos quais se produz, no ensino fundamental, o fracasso escolar mais acentuado entre crianças negras

Estudo sobre a afetividade presente na interação racial, a partir da implantação da política de cotas para negros na

Universidade de Brasília

Avaliar (1) a consistência entre cor/raça autoclassificada e determinada por entrevistador segundo variáveis

socioeconômicas e demográficas e (2) a magnitude das desigualdades étnicoraciais de renda e condição socioeconômica utilizando cor/raça autoclassificada e heteroclassificada.

Compreender os efeitos da discriminação racial na identidade e subjetividade de mulheres negras atendidas no programa SOS Racismo/Porto Alegre/RS

Investigar interações sociais entre meninas negras e brancas em contexto lúdico estruturado

Pesquisa qualitativa

Compreender o discurso social de uma criança de 9 anos de idade, procurando interpretar os seus mundos vividos e também os imaginados

Ressaltar processos aos quais a pessoa negra está submetida na construção de sua identidade, enfatizando aqueles que ocorrem em situações cotidianas principalmente na família, na escola e no trabalho

Analisar as dinâmicas interacionais de jovens frequentadores de bailes Charme no Rio de Janeiro,

Pesquisa qualitativa

Pesquisa qualitativa

Pesquisa qualitativa

Pesquisa etnográfica

Analisar a produção de sentidos na autonarrativa de uma professora negra ao construir seus projetos identitários concernentes à trajetória escolar e profissional, aos arranjos afetivoconjugais face ao seu pertencimento racial.

Conhecer como crianças de 9 a 12 anos se autocategorizam em comparação à categorização racial que é atribuída a elas, como discriminam racialmente com base em estereótipos e como avaliam concretamente outras crianças em relação à cor de pele e fenótipo.

Avaliar se a identidade racial apareceria espontaneamente e, caso sim, em quais situações
Pesquisa qualitativa

Pesquisa qualitativa

Pesquisa qualitativa 


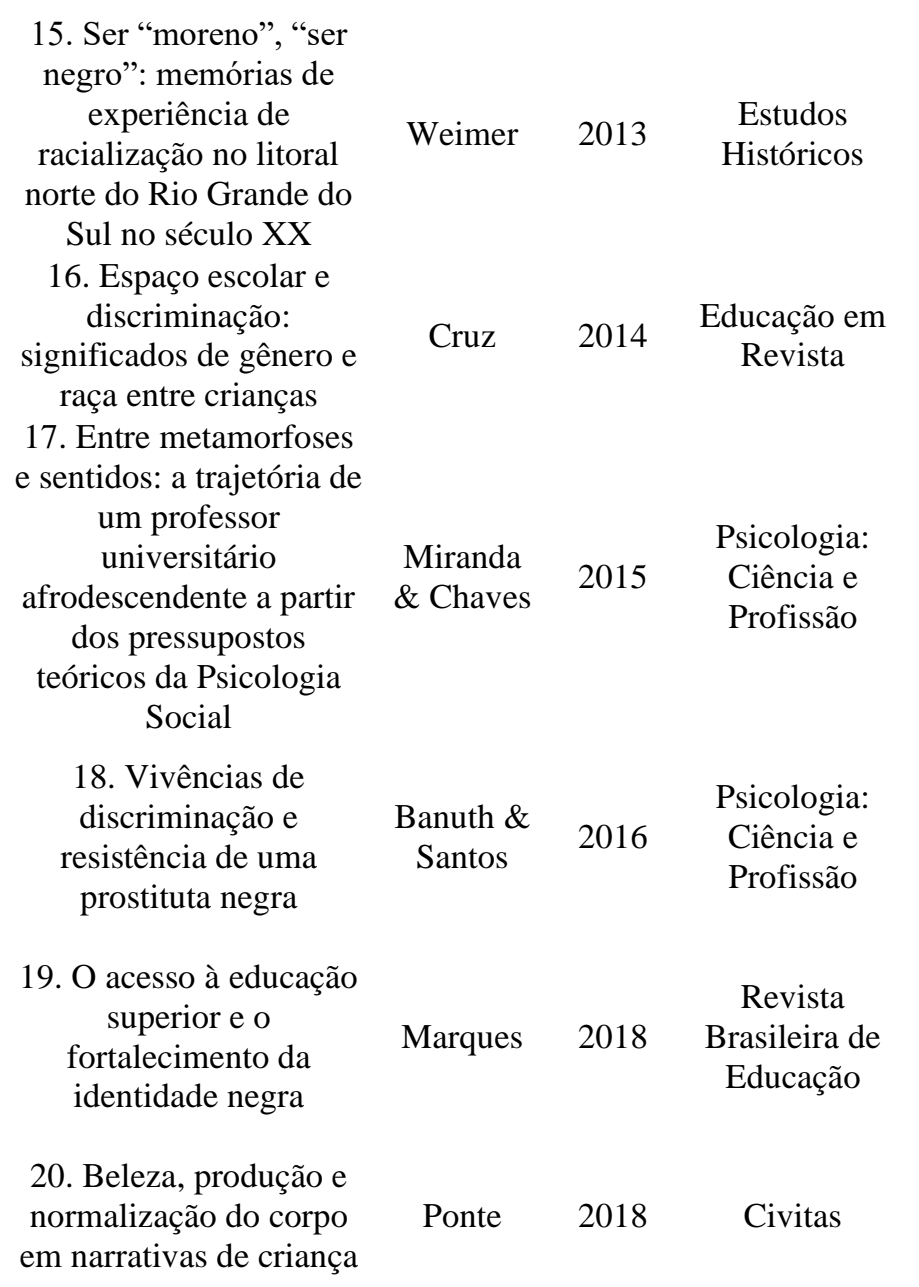

Estudar a passagem da designação racial de "moreno" para "negro" no litoral norte do Rio Grande do Sul, entre a geração de netos e bisnetos de escravos, isto é, entre meados do século XX e início do século XXI.

Saber como meninos e meninas construíam suas relações no cotidiano escolar e como estabeleciam estratégias de sobrevivência em uma sociedade desigual.

Analisar as configurações e contradições dos sentidos do processo identitário do sujeito selecionado: um professor universitário afro-descendente brasileiro

Compreender as vivências de exclusão, discriminação e resistência de uma profissional do sexo negra, que trabalhava em uma casa de prostituição do interior de São Paulo

Discutir sobre a afirmação da identidade negra dos estudantes ingressantes pelo sistema de cotas nos cursos de graduação

da Universidade Federal da Grande Dourados

Compreender sobre a produção da imagem corporal de crianças entre seis e doze anos, frequentadoras de salões de beleza em Brasília.
Pesquisa etnográfica

Pesquisa qualitativa

Pesquisa qualitativa

Pesquisa qualitativa

Pesquisa com análise documental

Pesquisa etnográfica

Nota: Tabela elaborada pelos autores.

\section{Características dos estudos encontrados}

As publicações selecionadas para realização deste trabalho concentraram-se principalmente no período entre 2011 e 2012. Esta constatação expressa um interesse dos profissionais e da sociedade no assunto. Além disto, a relevância e complexidade do tema demandam que investigações continuem sendo realizadas pelos pesquisadores na área abordada.

Na maioria, os trabalhos referiram-se a pesquisas qualitativas. Os procedimentos utilizados para coleta de dados variaram em: entrevistas individuais e grupais; observações em bailes de música charme (um estilo de música negra), salas de aula e salões de beleza étnicos; rodas de diálogo; sessões estruturadas (sociodrama) e semiestruturadas de interações; aplicação de questionário. Inferiu-se que a pesquisa qualitativa possibilitou uma exposição mais livre das ideias dos entrevistados, de forma que se observou como o processo de branqueamento foi vivenciado por cada indivíduo.

Tal levantamento expressou também a disparidade no número de publicações entre as regiões brasileiras e evidenciou a carência sobre o assunto em determinadas localidades no cenário nacional. Em que pese o objetivo do presente estudo não fosse a problematização da questão da construção e organização socioespacial da produção científica no Brasil, é impossível não frisar que tais desigualdades na produção do conhecimento refletem a totalidade social, que "é sempre a conjuntura histórica e forma social que recebe seu sentido dos processos sociais que se expressam através de variáveis sociais, econômicas e políticas" (Araújo, 1985, p.18). Assim, não é sem razão 
que a maioria das instituições de ensino superior e pesquisa se encontram no Sudeste do país, bem como essa região é a que mais tem contribuído para a produção científica nacional, dispondo de recursos humanos, financeiros e de infraestrutura (Fundação de Amparo à Pesquisa do Estado de São Paulo [FAPESP], 2011).

O perfil das populações investigadas contemplou indivíduos negros do gênero masculino e feminino. Seis artigos abordavam pesquisas realizadas com crianças $\mathrm{e}$ adolescentes com idades entre 8 e 18 anos e nove estudos com adultos com idades entre 20 e 90 anos. Cabe salientar que cinco dos 20 artigos incluídos neste estudo não especificaram as idades dos entrevistados. Entretanto, pelo contexto, foi possível deduzir as faixas etárias dos participantes: dois dos estudos foram realizados com alunos da $3^{\mathrm{a}}$ e $4^{\mathrm{a}}$ séries, o que indica idades entre 8 e 10 anos; em um estudo a entrevistada foi uma professora, o que induz se tratar de uma pessoa adulta; e outros quatro dos entrevistados eram indivíduos inseridos no mercado de trabalho e/ou na universidade, o que sugere também se tratar de pessoas adultas.

\begin{abstract}
Destaca-se ainda que a omissão destes dados nestas quatro publicações não comprometeu o entendimento dos resultados obtidos pelos pesquisadores. Contudo, a fim de evitar inferências desta natureza por parte dos leitores, é ideal que os pesquisadores atentem para estes aspectos e procurem reportar em seus estudos tais dados pela relevância para a compreensão do tema abordado. Ademais, a discriminação racial é uma situação com a qual os indivíduos negros se deparam ao longo de sua vida. Contudo, as formas como se manifesta, bem como seus efeitos e consequências, podem variar de acordo com a idade dos indivíduos. Por esta razão, para melhor entendimento de como esta dinâmica determina e influência no processo de branqueamento dos negros, ter acesso às experiências de indivíduos em variadas faixas etárias mostra-se imprescindível.
\end{abstract}

Os contornos do processo de branqueamento
Os conteúdos das publicações selecionadas foram agrupados e serão apresentados e discutidos em blocos a partir de quatro categorias criadas a posteriori, cujos significados emergiram da própria leitura dos artigos: (a) tornar-se branco para ser aceito; (b) estratégias de resistência frente ao processo de branqueamento; (c) ressignificação da identidade negra e (d) mito da democracia racial.

\section{Tornar-se branco para ser aceito}

Os estudos revelaram que as vivências relatadas expõem a existência de um processo de assimilação do "embranquecimento", que se estabelece nas experiências vividas ao longo da vida do indivíduo negro. Tais vivências ocasionariam uma tendência desta parcela da população a tentar se aproximar do padrão ideal e normalizador, neste caso o branco, e se afastar de sua ancestralidade africana. Em sua maioria, os artigos trazem que este processo se expressa através da rejeição da afrodescendência (Gomes, 2002; Carvalho, 2004; Nery \& Conceição, 2006; Silva \& Branco, 2011; Ferreira \& Camargo, 2011; Medeiros, 2011; Máximo, Larrain, Nunes, \& Lins, 2012; Cruz, 2014; Ponte, 2018).

No estudo de Carvalho (2004), observou-se a dificuldade de os indivíduos definirem-se como "pretos" ou "pardos", optando por definições como "moreno-escuro" ou "moreno-claro" ou "meio branco, meio moreno", entre outras denominações. A autora acredita que tal fato é devido à carga negativa ao qual está associada às definições "preto" e "pardo". O estudo demonstrou, ainda, que o branco aparece como referência e quase como a alternativa certa entre as opções de resposta. Nery e Conceição (2006) reforçam esta ideia em seu estudo, pois, através da técnica de sociodrama, observaram que os indivíduos negros não deixavam em evidência sua identidade negra. Assim, mesmo em um ambiente microssociológico, ficou perceptível a necessidade de inserção do negro no grupo dominante, de forma a se preservar de situações de exclusão. 
Gomes (2002), Medeiros (2011), Silva e Branco (2011) e Silva e Leão (2012) revelaram com suas pesquisas que a rejeição pela população negra de suas características vai além da dificuldade em definir-se como negro ou em reconhecer sua ancestralidade africana. Existe a crença - alimentada não somente pela invisibilidade das próprias características, mas também pela supervalorização das características do branco - de que as características precisam ser modificadas para serem aceitas (Silva \& Branco, 2011). O ápice deste processo de rejeição acarretaria a perspectiva futura de suprimir tais características percebidas como negativas e obter, mesmo que artificialmente, as tidas como positivas. Ponte (2018) reforçou essa percepção ao constatar nos salões de beleza nos quais fez sua pesquisa essa mesma perspectiva: ser magro e ter cabelo liso seria estereótipo ideal.

A manipulação do cabelo do indivíduo negro, sobretudo da mulher negra, retrata o quadro referido acima. A técnica mais utilizada na infância é a trança no cabelo das meninas. $\mathrm{Na}$ adolescência e idade adulta é o alisamento dos fios pelo uso de produtos químicos e de instrumentos como "pente", "ferro-quente", além da chapinha. A negação desta pertença racial, expressa pela manipulação do cabelo, é construída numa sociedade racista marcada pela presença de estereótipos e práticas racistas implícitas, ou até mesmo explicitas, que conferem ao negro o status de inferioridade e pode acarretar no sentimento de baixa autoestima (Gomes, 2002).

O estudo de Ferreira e Camargo (2011) corrobora com a ideia de que as condições sociais as quais é submetida a população negra suscitam a desvalorização de suas características físicas e, ainda, promovem a crença de incapacidade intelectual. Os referidos autores defendem que no Brasil o brancoeuropeu é tido como referencial de superioridade étnica e, em contrapartida, o negro é encarado como étnica e culturalmente inferior. Desta forma, compete ao indivíduo negro rejeitar sua ancestralidade africana e buscar se enquadrar no padrão ideal e inatingível do branco.

Cabe ressaltar que o processo de branqueamento é construído tanto no contexto privado (relações familiares) quanto no público (relações sociais mais amplas) como assinalam vários estudos aqui revisados (Ferreira \& Camargo, 2011; Silva \& Leão, 2012; Cruz, 2014; Máximo et al., 2012; Miranda, \& Chaves, 2015). Constatou-se que no contexto familiar o indivíduo negro aprende os primeiros preceitos racistas, sendo ensinado a rechaçar suas características marcadamente negras (Silva \& Leão, 2012). O estudo de Ferreira e Camargo (2011) aborda, por sua vez, que diante de situações de discriminação racial a família do indivíduo negro tende a se omitir e não tratar sobre o assunto. Visa, ainda, utilizar de elementos de identificação que a aproxime do grupo dominante e a afaste da realidade, como por exemplo denominar-se de "moreno". Estes mecanismos contribuem para a desqualificação de sua negritude e para a busca da reprodução do padrão hegemônico.

No contexto público escolar, espaço onde também ocorre a difusão da ideologia dominante, o indivíduo negro se depara com situações adversas que prejudicam a construção de uma identidade negra positiva (Ferreira \& Camargo, 2011). Nas interações infantis surgem os apelidos pejorativos para as meninas, tais como, "cabelo de bombril", "nega do cabelo de vassoura" "canhão" e para os meninos "negão", "preto", "carvão" e "macaco". Assim, a desqualificação das feições físicas faz com que estes indivíduos possam alimentar o desejo de branqueamento. $\mathrm{O}$ cabelo crespo aliado à cor da pele são os marcadores da raça negra e os principais alvo do racismo, de forma que é através destes que se expressa a aspiração do embranquecimento (Cruz, 2014).

Em seu estudo Silva e Branco (2011) apresentam algumas observações feitas a partir de uma sessão lúdica realizada em uma escola com duas meninas negras e duas meninas brancas. Os autores constataram que desde as socializações infantis já ocorrem a manifestação de crenças, valores e padrões de 
beleza racistas, que podem ocasionar na criança negra uma visão negativa de si. Nas interações ficaram claras as demonstrações de desvalorização das características típicas dos indivíduos afrodescendentes, o que dificulta a construção de uma identidade racial positiva. Alertam, ainda, que o padrão estético dominante acarreta preconceito contra as características dos indivíduos negros ao passo que supervaloriza as dos indivíduos brancos. Além disso, definem que este cenário dificulta a construção de uma noção de "pertencimento étnico-racial positiva e, com isso, um saudável desenvolvimento e constituição de Self" (Silva \& Branco, 2011, p. 204).

No estudo realizado em adultos com idades entre 20 a 60 anos, constatou-se que a escola foi um espaço significativo na experiência com sua negritude, sobretudo ao corpo negro e cabelo crespo. Estes indivíduos narraram que neste ambiente ocorreram situações reforçadoras dos estereótipos e representações negativas acerca de sua pertença racial e seu padrão estético (Gomes, 2002). A autora acredita que a escola, assim como a sociedade, deixa marcas profundas nos indivíduos negros ao emitirem sua opinião sobre seu corpo, cabelo e estética, de forma que estes indivíduos só passariam a ter uma visão positiva destes aspectos ao se afastarem do contexto escolar ou passassem a conviver em outros ambientes sociais. Entretanto, considera-se que estes espaços devem ser capazes de favorecer a ressignificação da negritude. Contudo, espera-se que o processo de reconstrução de uma identidade negra positiva parta, sobretudo, do próprio indivíduo negro. Pois, conforme argumenta Júlio (2011), cabe a esta parcela da população brasileira, oprimida em seus direitos, romper com as imposições da hegemonia branca e se apropriar de sua ancestralidade africana.

Ainda ao que se refere à esfera pública, Miranda e Chaves (2015) assinalam em seu estudo que o sujeito negro, bem como a maioria da população brasileira, não é educado para "conviver com as diferenças", posto que o contexto prega uma homogeneidade onde a construção de relações interraciais se dá de forma conflituosa, alicerçada na ambivalência (ocultação e revelação da raça). Desse modo, "a conquista de novos espaços - a circulação por ambientes diferentes do contexto familiar ou da comunidade - pode resultar no distanciamento da dimensão racial de sua identidade" (Souza, 1983 apud Miranda; Chaves, 2015, p. 593). Nesse diapasão, alguns sujeitos negros, ao conquistarem ascensão social, optam por assumir uma posição de "não-lugar" e "nãocondição", ocultando sua afrodescendência - de forma a não abordar questões raciais para resguardar do racismo.

O estudo de Bastos, Peres, Peres, Dumith, \& Gigante (2008) expõe outro aspecto relevante quando a questão envolve a condição socioeconômica em relação a condição racial. A classificação sobre a pertença racial de um indivíduo é influenciada por diversos fatores, como por exemplo, o ambiente social e seus atributos físicos pessoais. Em um contexto de pesquisa para realização de estudos, dentro de um recorte étnico-racial, foi possível observar como indivíduos em situação social mais favorável foram "branqueados" na ótica do entrevistador. Em oposição aos indivíduos em situação menos favorável, que apresentaram tendência a serem categorizados em grupos mais escuros pelos entrevistadores.

A ideologia de branqueamento prejudica a construção de uma identidade afrodescendente positiva. Tal tese eugenista é datada do século 19, defendendo a miscigenação como algo positivo, por conta que a "mistura de raças" proporciona a sobreposição dos caracteres biológicos relacionados ao branco sobre as outras raças, o índio e o negro, "embranquecendo" a população brasileira através das gerações (Lacerda, 1911). Ela ainda tem implicações práticas nas relações cotidianas dos brasileiros, aparecendo na busca "do sucesso econômico, por meio do cultivo de amigos e conhecidos brancos, por meio da adoção consciente das normas e comportamento da vida dos brancos de classe média" (Andrews, 2006). 
No estudo de Bento (2012), o "ideal de branqueamento" é frequentemente entendido como um problema do indivíduo negro, já que este não estaria satisfeito com sua condição e buscaria uma identificação com o indivíduo branco. Contudo, salienta a autora, trata-se de um processo mantido pelos detentores do poder, que se definiram como o padrão de referência e cada vez mais promovem o fortalecimento da autoestima e autoconceito de seu grupo em detrimento dos outros. A consequência deste sistema é uma visão extremamente desfavorável que prejudica a identidade racial e a autoestima do sujeito negro, além de responsabilizá-lo pela discriminação sofrida.

Desse modo, os estudos referidos evidenciaram que "tornar-se branco para ser aceito" se revela como uma estratégia de defesa psíquica frente ao sofrimento que o racismo acarreta. Nogueira (1998) já salientava que, não obstante a abolição, permaneceria por tempo indeterminado o cativeiro psíquico de uma imagem que, com o crivo da ciência, justificaria uma "inumanidade" do negro. Somado a isto, como herança do racismo, resta ainda o sentimento de falta de humanidade e pertencimento que conduz muitos negros a rejeitarem a sua conformação física e se tornarem desejantes de características que os aproximem "do branco", para se afastarem do estigma da raça.

\section{Estratégias de resistência frente ao processo de branqueamento}

Como estratégia de resistência o indivíduo negro volta a atenção para si mesmo e se afasta do papel lhe atribuem. Ele busca, assim, não se identificar com uma identidade que fora construída pelo outro e que lhe confere um lugar de menos-valia e submissão. Estes indivíduos adotariam uma conduta de autotransformação se impondo diante de situações que o desqualifiquem e o desabonem. Trata-se de indivíduos cientes das construções identitárias que lhes privam de escolhas e limitam suas preferências e mobilidade (Silva, Moura, \& Lopes, 2012.
Uma das participantes entrevistadas pelos referidos autores acima narrou diversas ocasiões nas quais teve que se posicionar, renegando a identidade que lhe atribuíam. Ela conta que na escola tinha somente uma colega e recorda de uma cena na qual a professora a chamou de negra e a empurrou. Em situações como esta, ao invés se retrair, disse que recorria aos estudos, distanciando-se de um papel que estava sendo construído para ela, mas não por ela. Em consequência, passou a se destacar entre os alunos, sendo convidada a participar de apresentações de poesias. Era vista na escola como uma menina inteligente e que lia bem. A participante conta, ainda, que na faculdade ouvia comentários racistas do tipo "isso é coisa de negro", ou então, "negro é bicho safado". Magoada e triste, recebia dos colegas a explicação de que não seria com ela, pois a viam como "uma negra diferente", "uma negra de alma limpa". Sua reação mais uma vez era de não se abater, pois reconhecia seu valor, de forma que cada vez estudava mais para estar entre os melhores.

Além disto, Banuth e Santos (2016) constataram em seu estudo que a entrevistada, uma mulher negra que trabalhava em uma casa como profissional do sexo, demonstrou estratégias de resistência diante do racismo e os seus mecanismos de ação. Em algumas situações, nas quais as colegas brancas expressavam construções generalizadas e depreciativas a respeito das pessoas negras, a entrevistada se posicionava não aceitando as atitudes discriminatórias. $\mathrm{O}$ enfrentamento surgia na tentativa de desconstruir a categorização diferenciada e distante a qual as colegas atribuíam aos indivíduos negros. Ela demonstrava se sentir diferente das demais, mesmo pertencendo ao mesmo gênero e desempenhando a mesma atividade de trabalho. Entretanto, a mulher não aceitava a posição de inferioridade e reagia assumindo sua negritude.

Deste modo, torna-se evidente que a discriminação racial acompanha os negros ao longo de sua vida. Estes indivíduos passam por situações que causam mágoa, tristeza, humilhação, raiva, entre outros sentimentos 
desagradáveis. Entretanto, indiscutivelmente, a maior das consequências é a resignação. Esta acarreta desistência da luta por espaço, o que consequentemente serve como combustível mantenedor desta engrenagem social que confere ao negro uma situação desfavorável. Logo, se um indivíduo não consegue reconhecer seus valores e capacidades, parece difícil motivar-se a travar uma luta dada como perdida. Assim, acabariam por adotar uma postura que perpetua sua condição e reforça seu estigma de inferioridade.

Todavia, muitos sujeitos negros elaboram psiquicamente "Estratégias de resistência frente ao processo de branqueamento" e, para não "embranquecer", passam por um processo de tomada de consciência das diferenças entre negros e brancos enquanto grupos raciais. A esse processo, Munanga (2012) chamou construção de uma "negritude", que se revela como uma inversão dos sentidos negativos associados a identidade negra e uma reconstrução interna de significados sobre "ser negro".

\section{Ressignificação da identidade negra}

Estudos apontam que apesar da construção da identidade do indivíduo negro ser marcada por experiências discriminatórias, que o direcionam a assimilação do processo de "embranquecimento", muitos destes indivíduos conseguem ressignificar positivamente o que é ser negro. Esta reconstrução varia de acordo com cada indivíduo e ocorre nas relações que estabelece tanto no contexto público quanto no privado (Gomes, 2003; Oliveira, Meneghel, \& Bernardes, 2009; Ferreira \& Camargo, 2011; Silva \& Leão, 2012; Weimer, 2013; Miranda \& Chaves, 2015; Marques, 2018).

Em alguns casos, espaços nãoeducativos, como os salões de cabeleireiro étnicos, podem se apresentar como um ambiente promovedor da ressignificação da identidade negra, principalmente ao que se refere ao corpo e cabelo. Estes locais expressam toda a inquietude e os conflitos que caracterizam a construção da identidade do indivíduo negro brasileiro. Assim, "nesses espaços, a identidade negra enquanto processo, é problematizada, discutida, afirmada, negada, encoberta, rejeitada, aceita, ressignificada e recriada" (Gomes, p. 178, 2003). Cecchetto, Monteiro e Vargas (2012) ressaltam em seu artigo ser perceptível a inversão de valores ao que tange à identidade negra em determinados contextos. Os autores observaram que a condição racial do indivíduo negro em um espaço de música negra, neste caso o "Charme", se mostrou como algo positivo e um diferencial favorável.

Apesar da negação e das tentativas de ocultação da cultura negra em detrimento a um padrão branco europeu, muitos indivíduos negros brasileiros conseguem se reinventar. O resgate da afrodescendência passa por um longo processo. Este vai desde a aceitação das características marcadamente negras, como o cabelo, até o uso de acessórios como turbantes, colares, entre outros.

Contudo, este movimento não se refere exclusivamente a questão estética, mas sim a um símbolo de resistência e de valorização negra diante de uma sociedade construída por negros e dominada por brancos (Matos \& Silva, 2014). Nessa direção, vários editoriais de moda exaltam a beleza negra e expondo a crescente força desse fenômeno atual. Existem, ainda, sites, blogs, vídeos, páginas em redes sociais, uma série de canais abordando a questão do retorno às raízes africanas. São espaços onde, por exemplo, os participantes trocam dicas, truques e orientações de moda e cuidados de beleza específicos para a população negra. Estes canais serviriam, sobretudo, como fortalecedores da construção de uma identidade negra positiva, de forma que seus participantes encontrariam uns nos outros um ponto de apoio, acolhimento e representatividade.

Para a promoção de uma identidade negra positiva, romper com o silêncio e discutir sobre as experiências de discriminação possibilita que os indivíduos percebam o vigor de sua luta e reconheçam de que há muito do que se orgulhar, já que a história do negro é marcada por batalhas. Suas estratégias de resistência abrangem ações individuais, através 
das quais o indivíduo se percebe alguém com garra e espírito de luta. Mas também através de ações coletivas, tais como: "o diálogo, a atuação cidadã, a busca de referências culturais, a militância política e a participação em movimentos sociais, especificamente o movimento negro" (Oliveira et al., p. 271, 2009).

O artigo de Ferreira e Camargo (2011) apresenta que o processo terapêutico também se mostra como aliado na reconstrução positiva da identidade negra. Por se tratar de um espaço que possibilita romper o silêncio e a libertar os sentimentos oprimidos, auxilia na busca pelo autoconhecimento e o contato com ancestralidade africana.

Além disto, indivíduos que ascenderam socialmente passam a se identificar como negros (Silva \& Leão, 2012). Os autores acreditam que essa identificação, ocorrida paralelamente à mobilidade social, é em virtude da consciência adquirida por estes indivíduos de estar em um espaço majoritariamente branco. A disponibilidade de um novo repertório sobre a negritude, antes inexistente, também contribui para indivíduo se identificar como negro. Os depoentes, em especial os homens, trazem que hoje existe um modismo em ser negro no Brasil. Fato que possibilita a adoção da identidade cultural africana em detrimento de outras. Faz com que os indivíduos negros valorizem determinado traços, antes omitidos, como estilo de cabelo e roupas de caráter africano.

Weimer (2013) apresentou em seu artigo outro aspecto interessante. $\mathrm{O}$ autor salientou que sua pesquisa não tinha o objetivo de desenvolver teoria extensiva ao restante da população negra, pois reconhecia que seu resultado era limitado. Entretanto, pode perceber que a condição como indivíduo negro no Brasil ia além de questões fenotípicas reveladoras da ancestralidade africana. Um entrevistado em especial, descendente de "morenos", como ele definia os negros, alegava que, apesar de suas características físicas serem de pessoa branca, existia um sentimento de coletividade que fazia com que se identificasse com os indivíduos negros.

O acesso da população negra ao ensino superior não traz somente desafios peculiares a essa parcela de indivíduos, como também proporciona um cenário para a construção de uma identidade negra positiva, uma vez que "o ambiente acadêmico proporciona a esses estudantes uma ampliação das suas perspectivas de vida não só profissionais, mas também culturais e de desenvolvimento pessoal" (Lemos, 2017, pp. 20-21). Outrora um espaço majoritariamente ocupado por pessoas brancas, as políticas públicas de financiamento estudantil (Programa Universidade Para Todos, Prouni, e o Programa de Financiamento Estudantil, FIES, nas Instituições de Ensino Superior Privadas) e as ações afirmativas (as cotas sociais e étnico-raciais, nas Instituições Públicas Federais e Estaduais) transformaram as universidades em um ambiente mais democrático, diversificado e heterogêneo (Ristoff, 2014). Atividades como grupos de estudos e pesquisas, bem como as disciplinas de caráter sociológico, possibilitaram aos negros acadêmicos o desenvolvimento de uma consciência étnico-racial construtiva, contribuindo para o resgate da história do povo negro e, por consequência, o fortalecimento da identidade ancestral africana (Marques, 2018).

Ser negro no Brasil vai além de carregar traços de ascendência africana. É partilhar de uma mesma história marcada por escravização de um povo, desenraizamento de sua pertença racial e discriminação por sua raça/cor. Ser negro é se conscientizar da ideologia fictícia criada sobre si que lhe confere uma imagem inconsistente, mas na qual se reconhece. É ressignificar sua existência respeitando as diferenças e se posicionando de forma a não se submeter às imposições do outro. Ser negro é contestar a imposição do padrão hegemônico branco e construir uma vivência a partir das próprias escolhas (Souza,1983). Assim, o fenômeno de "tornar-se Negro" e os sentidos positivos desse vir a ser revelam a "Ressignificação da identidade negra".

Mito da democracia racial 
O estudo de Silva e Leão (2012) explora a questão do mito da democracia racial, de forma que segundo alguns depoentes, não haveria desigualdades entre brancos e negros, mas sim segregação econômica e social. Apesar das experiências de discriminação racial sofridas, muitos indivíduos negam a existência do racismo. Assim, fica exposto o quanto é intensa a construção social de invisibilidade e naturalidade do racismo (Oliveira et al., 2009). Nery e Conceição (2006) explicam que o racismo na atualidade assumiu uma versão menos direta e explícita, diferente das manifestações no passado. Tal fato acarreta a falsa crença de igualdade racial e dificulta a consciência e atuação no combate ao racismo.

Mesmo que indivíduos negros e brancos sejam pobres, ou seja, desfrutem da mesma condição social e econômica, "o branco tem o privilégio simbólico da brancura, o que não é pouca coisa" (Bento, 2012, p. 27). Lançar olhar para as desigualdades sociais sem considerar a questão racial é limitador. É notório que os indivíduos negros em situação de pobreza possuem desvantagens em todas as esferas da vida se comparados aos brancos na mesma situação. Seu acesso ao que se refere a saúde, educação e mercado de trabalho é limitado. Os negros saíram do sistema escravagista com prejuízo considerável. Estabeleceu-se um silêncio ao que se refere aos benefícios concretos e simbólicos apropriados pelos brancos. Afinal, falar sobre $\mathrm{o}$ assunto implicaria em prestação de contas, compensação, indenização para os negros, colocando os privilégios dos brancos em disputa.

Nesse diapasão, existe no Brasil a crença individual de isenção de preconceito racial, curiosamente paralela ao reconhecimento da existência do racismo. Ora, a sociedade reconhece que se vive em um país racista, mas as pessoas não se consideram racistas (Kon, Silva, \& Abdud, 2017). Sales (2006) elucida que se consolidou no Brasil um "não-dito racista", profundamente atrelado às relações "cordiais", paternalistas e patrimonialistas de poder, como um "pacto de silêncio entre dominados e dominadores".

Ainda segundo o autor, tal "não-dito" é uma forma de dizer algo sem, contudo, responsabilizar-se pelo que se diz, derivando daí o emprego do "discurso racista de uma diversidade de recursos tais como implícitos, denegações, discursos oblíquos, figuras de linguagem, trocadilhos, chistes, frases feitas, provérbios, piadas e injúria racial, configurando a não-intencionalidade da discriminação racial" (Sales, 2006, p.258). Um grande problema dessa questão reside na dificuldade de pessoas brancas em reconhecerem a posição privilegiada que ocupam e as oportunidades que desfrutam em oposição aos acessos negados ou obstaculizados às pessoas negras.

Assim, observa-se que a população em geral tem uma visão limitada sobre o racismo, entendendo que esse seria determinado por atitudes individuais ostensivamente agressivas e ações discriminatórias positivas apenas, ignorando o alicerce sociopolítico que coloca negros e brancos em desigualdade. Tal perspectiva restringe a compreensão da estrutura desigual que vivem brancos e negros no Brasil. Esse fato, que se mostra no "Mito da democracia racial", acarreta a manutenção da crença deturpada de uma sociedade igualitária e dificulta a tomada de ações de combate às desigualdades (Oliveira, \& Barreto, 2003).

Cabe salientar que a hipótese de que o fundamento das desigualdades no Brasil não é a raça, mas sim segregação econômica e social (Souza, 2005), poderia comprometer este processo de construção identitária já que no Brasil há "a dificuldade de perceber a dimensão da questão racial trava o processo de construção e constituição do país como nação" (Kon et al., 2017). Os indivíduos negros ao validarem o mito da democracia racial, passariam, por exemplo, a crer que os obstáculos para sua ascensão social e econômica estariam intimamente ligados à sua capacidade. Nogueira (1998) ao evidenciar que não é incomum o sentimento experimentado por alguns negros de nunca ser suficientemente 
bons nas relações ou funções sociais assumidas e, numa tentativa de suturar tal ferida e buscarem reconhecimento, lançarem-se conscientes ou não - "na cruel e incansável tarefa de ser o melhor". Assim, diante de um possível fracasso, sentiriam-se incapazes, não reconhecendo que sua mobilidade social e acesso econômico são dificultados, sobretudo, por sua pertença racial.

\section{Considerações finais}

O presente estudo realizou uma revisão da literatura nacional, apresentou e discutiu as principais características encontradas nos artigos selecionados acerca do processo de branqueamento da população negra no Brasil. Os resultados tornaram evidente que diversos contextos podem apresentar situações que menosprezem as caraterísticas raciais de seus membros.

Desde a infância, as crianças lidam com constructos potencialmente danosos e durante $o$ constante processo de introjeção e assimilação do meio que a circunda e no decorrer destas transformações poderá validar tais constructos. As interações sociais seguintes, geralmente ocorridas no ambiente escolar, por vezes, são marcadas por manifestações de discriminação racial. Em contato com realidades desqualificadoras de seus atributos raciais, a criança negra passaria a desejar ser branca. Assim, espera-se que a família e a escola sejam ambientes onde o indivíduo negro, então criança ou adolescente, consiga desenvolver uma imagem positiva sobre si. Sugere-se que sejam espaços acolhedores dos conflitos identitários originados pelas vivências em uma sociedade racista que determina como padrão ideal o branco.
Ademais, os resultados compilados evidenciam que em outras esferas públicas como o espaço acadêmico ou laboral, neste caso em relação as atividades consideradas mais eruditas, a temática racial também possa ser abordada. Por ser um local de restrito acesso aos indivíduos negros, aqueles que conseguem ascender e se inserir neste contexto podem deparar-se com situações onde a discriminação racial seja praticada de forma natural e sem constrangimento algum.

Apesar de todos os entraves que o indivíduo negro encontra em sua trajetória de vida, muitos se mostram resistentes frente ao processo de branqueamento. Há outros, ainda, que sucumbem a este sistema e renegam sua pertença racial - contudo, em um segundo momento, alguns desses conseguem ressignificar positivamente sua identidade negra. $O$ ideal seria que indivíduos negros encontrassem um espaço onde pudessem romper com o silêncio e discutir sobre as experiências de discriminação racial.

A limitação para realização deste estudo foi a escassez de publicações nas bases consultadas sobre o processo de branqueamento do indivíduo negro brasileiro. Por esta razão, infere-se que possam existir aspectos não contemplados pelos artigos selecionados, mas que seriam relevantes para a construção de um entendimento mais profundo e abrangente sobre o tema. Contudo, apesar da deficiência de estudos, o conhecimento produzido pelo material examinado ressalta a importância da criação de espaços que promovam a troca de experiência entre estes indivíduos, em todas as idades, de forma que possam ressignificar sua negritude.

\section{Referências}

Almeida, S. L. (2018). O que é racismo estrutural?. Belo Horizonte: Letramento.

Andrews, G. R. (1998). Negros e brancos em São Paulo. São Paulo: Edusc.

Araújo, V. M. R. H. (1985). A organização espacial da informação científica e tecnológica no Brasil. Ciencia da informaçao, 14(1). Recuperado de http://revista.ibict.br/ciinf/article/view/223 Banuth, R. F., \& Santos, M. A. (2016).

Vivências de discriminação e resistência de uma prostituta negra. Psicologia: Ciência e Profissão, 36(3), 763-776. doi: $\underline{10.1590 / 1982-3703002862015}$ 
Bastos, J. L., Peres, M. A., Peres, K. G., Dumith, S. C., \& Gigante, D. P. (2008). Diferenças socioeconômicas entre autoclassificação e heteroclassificação de cor/raça. Revista Saúde Pública, 42(2), 324-334. doi: 10.1590/S0034$\underline{89102008005000005}$

Bento, M. A. S. (2012). Branqueamento e branquitude no Brasil. In I. Carone, \& M. A. S. Bento (Eds.), Psicologia Social do Racismo. Petrópolis: Vozes.

Carone, I. (2012). Breve histórico de uma pesquisa psicossocial sobre a questão racial brasileira. Psicologia social do racismo: estudos sobre branquitude e branqueamento no Brasil. Petrópolis: Vozes.

Carvalho, M. P. (2004). O fracasso escolar de meninos e meninas: articulações entre gênero e cor/raça. Cadernos Pagu, (22) 247-290. doi: 10.1590/S0104$\underline{83332004000100010}$

Cecchetto, F., Monteiro, S., Vargas, E. (2012). Sociabilidade juvenil, cor, gênero e sexualidade no baile charme carioca. Cadernos de Pesquisa, (42), 454-473. doi: 10.1590/S0100-15742012000200008

Costa, J. F. (1983). Da cor ao corpo: a violência do racismo. In N. S. Souza (Ed.), Tornar-se negro ou As Vicissitudes da Identidade do Negro Brasileiro em Ascensão Social. Rio de Janeiro: Graal.

Costa, A. B. C., \& Zoltowski, A. P. C. (2014). Como escrever um artigo de revisão sistemática. In S.H. Koller, M. C. P. de Paula Couto, \& J. Hohendorff (Eds.), Manual de produção científica (pp. 55-70). Porto Alegre, RS: Grupo A.

Cruz, T. M. (2014). Espaço escolar e discriminação: significados de gênero e raça entre crianças. Educação em Revista, 30 (1), 157-188. doi: 10.1590/S010246982014000100007

Fundação de Amparo à Pesquisa do Estado de São Paulo. (2011). Indicadores de ciência, tecnologia e inovação em São Paulo 2010. São Paulo: FAPESP.

Ferreira, R. F., \& Camargo, A. C. (2011). As Relações Cotidianas e a Construção da Identidade Negra. Psicologia: Ciência e
Profissão, 31(2). doi: 10.1590/S141498932011000200013

Gomes. N. L. (2002). Trajetórias escolares, corpo negro e cabelo crespo: reprodução de estereótipos ou ressignificação cultural? Revista Brasileira de Educação, 21. doi: 10.1590/S1413-24782002000300004

Gomes. N. L. (2003). Educação, identidade negra e formação de professores/as: um olhar sobre o corpo negro e o cabelo crespo. Revista Brasileira de Educação, 29(1), 167-182. doi: 10.1590/S151797022003000100012

Gomes. N. L. (2004). Uma dupla inseparável: cabelo e cor da pele. In L. M. A. Barbosa, P. B. G. Silva, \& V. R. Silvério (Orgs.), De preto a afro-descendente: trajetória de pesquisa sobre o Negro, Cultura negra e relações Étnico-Raciais no Brasil. São Carlos: EduFSCar.

Instituto Brasileiro de Geografia e Estatística (2013). Mapa da Distribuição Espacial da População, segundo a cor ou raça - Pretos e Pardos. Recuperado de ftp://geoftp.ibge.gov.br/cartas_e_mapas/ma pas_do_brasil/sociedade_e_economia/mapa s_murais/brasil_pretos_pardos_2010.pdf

Júlio, A. L. (2011). Por uma visão psicossocial da autoestima de negros e negras.

Protestantismo em Revista, 24, 62-69

Kon, N. M., Silva, M. L., Abdud, C. C. (2017) $O$ racismo e o negro no Brasil: questões para a psicanálise. São Paulo: Perspectiva.

Lacerda, J. B. (1911). Sobre os mestiços no Brasil. Primeiro Congresso Universal das Raças. Londres, 26-29. Recuperado de https://edisciplinas.usp.br/pluginfile.php/24 7540/mod_resource/content $/ 1 /$ Sobre $\% 20$ os \%20mesti\%C3\%A7os\%20do\%20Brasil.pdf

Lemos, I. B. (2017). Narrativas de cotistas raciais sobre suas experiências na universidade. Revista Brasileira de Educação, 22(71), e227161. doi: 10.1590/s1413-24782017227161

Lima, M. E. O., \& Vala, J. (2004). As novas formas de expressão do preconceito e do racismo. Estudos de Psicologia (Natal), 9(3), 401-411. doi: 10.1590/S1413294X2004000300002 
Lopes, V. N. (2005) Racismo, preconceito e discriminação. In K. Munanga. (Ed.), Superando o racismo na escola (pp. 185204). Brasília: Ministério da Educação, Secretaria de Educação Continuada, Alfabetização e Diversidade.

Matos, I. G., Silva, A. (2014). Vício Cacheado: estéticas afro diaspóricas. Revista da ABPN, 6(14), 214-235.

Recuperado de http://abpnrevista.org.br/revista/index.php/r evistaabpn1/article/view/139

Marques, E. P. S. (2018). O acesso à educação superior e o fortalecimento da identidade negra. Revista Brasileira de Educação, 23, e230098. Recuperado de http://www.scielo.br/pdf/rbedu/v23/1809449X-rbedu-23-e230098.pdf

Máximo, T. A. C. O., Larrain, L. F. C. R., Nunes, A. V. L., \& Lins, S. L. B. (2012). Processos de identidade social e exclusão racial na infância. Psicologia Política, 18(3), 507-526. doi: 10.5752/P.16789563.2012v18n3p507

Medeiros, A. B. (2011). Pobreza, relações étnico-raciais e cotidiano escolar: narrativas do viver. Revista Brasileira de Educação, 16(46), 167-189. doi: 10.1590/S141324782011000100010

Miranda, S. F., \& Chaves, M. M. P. (2015). Entre Metamorfoses e Sentidos: a Trajetória de um Professor Universitário Afro-Descendente a Partir dos Pressupostos Teóricos da Psicologia Social. Psicologia: Ciência e Profissão, 35(2), 584-598. doi: 10.1590/1982-370301332013

Moher, D., Liberati, A., Tetzlaff, J., Altman, D. G., \& Prisma Group. (2009). Preferred reporting items for systematic reviews and meta-analyses: the PRISMA statement. PLoS med, 6(7), e1000097. doi: 10.1371/journal.pmed.1000097

Munanga, K. (2004a). Uma abordagem conceitual das noções de raça, racismo, identidade e etnia. In Programa de educação sobre o negro na sociedade brasileira. Niterói: EDUFF.

Munanga, K. (2004b). A difícil tarefa de definir quem é negro no Brasil. Estudos
Avançados, 18(50), 51-66. doi:

10.1590/S0103-40142004000100005

Munanga, K. (2012). Negritude e identidade negra ou afrodescendente: um racismo ao avesso? Revista da Associação Brasileira de Pesquisadores Negros, 4(8), 6-14.

Recuperado de http://abpnrevista.org.br/revista/index.php/r evistaabpn1/article/view/246/222

Nery, M. P., \& Conceição, M. I. G. (2006). Política racial afirmativa e afetiva na interação intergrupal. Interação em Psicologia, 10(2), 363-374. doi: 10.5380/psi.v10i2.7695

Nogueira, I. (1998). Significações do corpo negro (Tese de doutorado, Instituto de Psicologia da Universidade de São Paulo, São Paulo). Recuperado de http://www.ammapsique.org.br/baixe/corpo -negro.pdf

Oliveira, C. L. P., \& Barreto, P. C. S. (2003). Percepção do racismo no Rio de Janeiro. Estudos Afro-Asiáticos, 25(2), 183-213. doi: 10.1590/S0101-546X2003000200001

Oliveira, M. L. P., Meneghel, S. N., \& Bernardes, J. S. (2009). Modos de subjetivação de mulheres negras: efeitos da discriminação racial. Psicologia e Sociedade, 21(2), 266-274. doi: 10.1590/S0102-71822009000200014

Ponte, V. P. (2018). Beleza, produção e normalização do corpo em narrativas de criança. Civitas, 18(1), 153-170. doi: 10.15448/1984-7289.2018.1.28328.

Ristoff, D. (2014). O novo perfil do campus brasileiro: uma análise do perfil socioeconômico do estudante de graduação. Avaliação: Revista da Avaliação da Educação Superior (Campinas), 19(3), 723-747. doi: $10.1590 /$ S141440772014000300010

Sales Jr., R. (2006). Democracia racial: o nãodito racista. Tempo Social, 18(2), 229-258. doi: 10.1590/S0103-20702006000200012

Silva, M. P. D., \& Branco, A. U. (2011). Negritude e infância: relações étnico-raciais em situação lúdica estruturada. Psico, 42(2), 197-205. Recuperado de http://revistaseletronicas.pucrs.br/revistapsi 
co/ojs/index.php/revistapsico/article/view/6 $\underline{516 / 6521}$

Silva, G. M., Leão, L. T. S. (2012). O paradoxo da mistura identidades, desigualdades e percepção de discriminação entre brasileiros pardos. Revista Brasileira de Ciências Sociais, 27(80), 117-133. Recuperado de http://www.scielo.br/pdf/rbcsoc/v27n80/v2 7n80a07.pdf

Silva, M. P., Moura, C. B., Lopes, F. M. S. R. (2012). Das batalhas identitárias às práticas de liberdade: histórias de vida de uma professora negra. Linguagem em (Dis)curso, 12(2), 545-571. doi: 10.1590/S1518-76322012000200008

Souza, J. (2005). Raça ou classe? Sobre a desigualdade brasileira. Lua Nova: Revista de Cultura e Política, (65), 43-69. doi: 10.1590/S0102-64452005000200003
Souza, N. S. (1983). Conclusão. In N. S. Souza (Ed.), Tornar-se negro ou As Vicissitudes da Identidade do Negro Brasileiro em Ascensão Social (77-78). Rio de Janeiro: Graal.

Schucman, L. V (2010). Racismo e antirracismo: a categoria raça em questão. Revista Psicologia Política, 10(19), 41-55. Recuperado de http://pepsic.bvsalud.org/scielo.php?script= sci_arttext;pid=S1519549X2010000100005

Valente, A. L. E. F. (1998). Ser negro no Brasil hoje. São Paulo: Moderna.

Weimer, R. de F. (2013). Ser "moreno", "ser negro": memórias de experiência de racialização no litoral norte do Rio Grande do Sul no século. Estudos Históricos, 26(52), 409-428. doi: 10.1590/S0103$\underline{21862013000200008}$

\section{Dados sobre os autores:}

- Sabrina Santos Silva: Psicologa.

- Luan Paris Feijo: Psicólogo, Mestre e Doutorando em Psicologia Clínica - Unisinos e Coordenador do Curso de Psicologia - Factum

- Thaise Mendes Farias: Psicóloga, Mestre em Ciência Política - UFPEL e Doutoranda em Psicologia Clínica - Unisinos

- Michele Poletto: Psicóloga e Psicanalista, Mestre e Doutora em Psicologia - UFRGS, Professora Universitária - FTEC/IBGEN direitos autorais para os artigos publicados são do autor, com direitos do periódico sobre a primeira publicação. Os autores somente poderão utilizar os mesmos resultados em outras publicações indicando claramente este periódico como o meio da publicação original. Em virtude de sermos um periódico de acesso aberto, permite-se o uso gratuito dos artigos em aplicações educacionais e científicas desde que citada a fonte conforme a licença CC-BY da Creative Commons. 